\title{
Quem é o outro, o diferente? Reflexōes sobre psicanálise e educação
}

Cristiana Carneiro*

\section{Resumo}

O presente artigo pretende pensar a concepção de destino em Freud como conceito que implica necessariamente uma reflexão acerca da natureza humana, já que se refere à trajetória temporal dos sujeitos. Tal iniciativa, a nosso ver, enriquece uma discussão quanto ao lugar do outro na ação educativa, questionamento indispensável para que uma prática inclusiva seja possível. As concepçóes de destino comportam significaçôes para "natureza humana" que influenciam a prática, já que incidem sobre o ideário que temos do outro. É nesta direção que a psicanálise nos indica um caminho: o conhecimento da verdade e desejo do próprio sujeito. Neste caso, a diferença não diria respeito apenas ao outro, mas refere-se ao próprio desconhecimento que cada um tem para consigo mesmo. Aceitar a diferença é poder conviver com a nossa própria condição de desconhecimento em relação a nós mesmos, é visualizar que o caminho humano estará sempre marcado por certa errância.

Palavras-chave: Destino; Sujeito; Psicanálise; Educação.

\footnotetext{
* Professora doutora da Universidade Federal do Rio de Janeiro, Rio de Janeiro, Rio de Janeiro, Brasil.
} 


\section{Who is the other, the different? Reflections on psychoanalysis and education}

\section{Abstract}

This article intends to think destination in Freud as a concept that necessarily implies a reflection on human nature, since it refers to the temporal trajectory of the subjects. This initiative, in our view, enriches a discussion about the place of the other in educational activity, essential for inclusive practice. The concept of destiny involves meanings for "human nature" that influence practice, since focus on the ideas we have of the other. It is in this direction that psychoanalysis shows us the way: the knowledge of the truth and desire of the subject itself. In this case, the difference would not only respect each other, but refers to an ignorance that each has for himself. Accept the power of difference is live with our own condition of ignorance about ourselves, is to visualize the human journey is always marked by some wandering.

Keywords: Destination; Subject; Psychoanalysis; Education.

\section{Introdução}

Como nos fala Sacristán (2000), a escolarização tem um propósito e existe porque funciona a partir de um projeto comum. Nesse sentido, não é mero receptáculo de aprendizes, não é uma ação espontânea, mas intencional e dirigida a certas finalidades. Para tanto, a busca de uma coerência do movimento educativo expressa essa intençáo coletiva, e certos mecanismos reguladores se constituirão como estratégias necessárias. Enfocando justamente "o papel aglutinante que desempenham as idéias e os significados sociais partilhados em torno da natureza humana" (SACRISTÁN, 2000, p. 49), acreditamos na centralidade deste mote simbólico como poder regulador. Ou melhor, ainda que existam em um plano simbólico, as idéias acerca da natureza humana subjazem como pano de fundo de qualquer política educativa. Nesse sentido, num aspecto micropolítico, o professor estará referido ao seu ideário particular de natureza humana - que por sua vez reflete o pensamento coletivo - em todas as suas açôes práticas, saiba ele ou não. Ao repreender, elogiar, acolher, exigir de determinado aluno, ele estará de alguma forma sendo dirigido pelos significados de ser humano que lhe atribui. Se aceitamos - ou não - o diferente, o fazemos também embasados por um ideário simbólico de quem é aquele que a nós se dirige e qual nosso lugar diante dele. Portanto, questionar nossa concepção de humanidade é, em última instância, uma ação política.

O presente artigo pretende, entáo, pensar a concepção de destino como conceito que implica necessariamente uma reflexão acerca da natureza humana já que se refere à trajetória temporal dos sujeitos, relacionando-a com a questão da liberdade. Tal iniciativa, a nosso ver, enriquece uma discussão quanto ao lugar do outro na ação educativa, questionamento indispensável para que uma prática inclusiva seja possível. 


\section{Sujeito e liberdade}

$\mathrm{O}$ que pode o sujeito diante de um corpo onde faltam duas pernas? E aquele que desde o nascimento não vê o mundo com seus olhos, ou não partilha o som com os demais? Ora, se de alguma forma a biologia não os equiparou à maioria, de forma alguma eles estarão isentos das questôes subjetivas que assolam a todos. Como já nos indicou Dolto (1992), uma criança sem um dos membros pode ter uma imagem inconsciente do corpo muito mais preservada do que uma que os possua. Não há regras pré-fixadas, a constituição psíquica envolve muito mais do que a biologia. Portanto, os questionamentos sobre nosso destino vão além de qualquer especialidade, gênero ou classe social, ainda que todos esses aspectos sejam condicionantes de nossa forma de ser e estar no mundo. Nesse sentido, as perguntas sobre o sujeito e sua destinação - compreendendo com isto sua trajetória numa existência temporal - são pertinentes enquanto característica humana de uma forma mais geral, ao mesmo tempo em que particularmente só poderão ser respondidas de forma idiossincrática, cada sujeito com sua história singular. É nesta direção que o pensamento freudiano nos oferece uma rica reflexáo sobre o destino, a partir do momento que articula destino e autonomia nos mostrando quão difícil este processo de construção de uma liberdade possível pode ser.

Em 1905 Freud ressaltava que uma das realizaçôes psíquicas mais importantes, e mais "dolorosas" que a puberdade colocaria em jogo para todos os humanos, seria o desligamento da autoridade dos pais (FREUD, 1905/1980, p. 213). Essa realização colocaria em cena a possibilidade de mudança do sujeito. Se, especificamente em relação à puberdade, Freud ressalta o mecanismo que possibilitaria ao sujeito uma mudança da posição de filho, submetido à autoridade dos pais, esse modelo não fica circunscrito à puberdade. $\mathrm{Na}$ ideia de destino ele nos mostra a possibilidade de mudança dos sujeitos em geral, assentada também sobre o rompimento com uma autoridade "exterior". A possibilidade de mudança apontaria para um além, onde de alguma forma, idiossincrática, os sujeitos teriam a possibilidade de buscar a "autorização" de ser, em si próprios.

O Destino ${ }^{1}$ como um ente super-poderoso, que comandaria o sujeito apesar dele, sendo exterior ao sujeito, é relacionado por Freud (1924/1980) com a autoridade da dupla parental. Ou seja, considerar o Destino com poderes supremos, desconsiderando qualquer relação pessoal, é de alguma forma conservar a autoridade parental, agora revestida de Destino. Encarar o destino como impessoal, e também tornar o destino pessoal, são duas facetas que em certos momentos parecem contraditórias. Ao apontar a importância do sujeito encarar o destino como impessoal, interpretamos que Freud está chamando a atençáo para a importância da consideraçáo do acaso, do abandono de uma postura animista, onde o destino seria compreendido como um ente que estaria constantemente "tramando" contra ou a favor do sujeito. Ao mesmo tempo, torná-lo pessoal, seria poder trazê-lo para si, no sentido de não ficar submetido a uma "autoridade" exterior, mas trazer essa autoridade para si próprio. Essa autonomia frente ao destino não deixou de ser considerada como uma árdua tarefa por Freud, já que libertar-se dela é de certa forma ter que se haver com um temor 
realista que temos da morte. Se, contrariamente, mantemos certa ilusão na sorte e nos poderes do destino conservamos a fantasia de que, de alguma forma, escaparíamos da morte $^{2}$. Nesse sentido, o que está em jogo aqui, é a atribuição de poderes a um outro. Modificar esta visão do destino, onde a sorte ou o azar premiariam ou puniriam o sujeito, é também desligar-se da autoridade, de uma subjugação vinda de "fora", o que na indicação freudiana parece ir muito além da puberdade.

A dificuldade desse desligamento se daria porque com ele também se perderia uma proteçáo imaginária, que credita ao outro a capacidade de nos proteger do desamparo ${ }^{3}$, confrontando o sujeito com o seu próprio desamparo. Nesse sentido, se libertar do Destino e construir uma destinação pessoal é uma tarefa favorecida pela puberdade, ela não terá porto de chegada, construindo uma história que só findaria com a própria vida. Se apenas muito poucos dentre nós conseguem escapar do poder sombrio do Destino (FREUD, 1924/1980) significa dizer que essa desvinculação de uma autoridade exterior, investida de poder, é difícil, não é universal, e talvez pouco generalizável.

Tal discussão nos remete à questão da liberdade. A liberdade em relação ao desligamento de uma autoridade exterior teria uma relação com a autonomia no sentido, justamente, de um campo de regulaçáo e escolhas que diriam mais respeito ao próprio sujeito. No entanto, Freud (1924/1980) ao dizer que poucos conseguem tornar o destino pessoal, está dizendo quáo difícil é essa empreitada de tomada de poder, possibilitadora de liberdade. Este modelo de pensamento freudiano desacreditou numa autonomia plena e atingível através da consciência, o que abalou o ideário (tão importante nos séculos XIX e início do XX) de que a razão finalmente nos libertaria. Estaria ele, então, desacreditando num projeto maior em relação à liberdade, sobretudo naquela referida à possibilidade de construçáo de um destino pessoal?

A "certeza de que o sujeito é idêntico a si mesmo" (GONDAR, 1995, p. 4), sonho máximo do racionalismo, cai por terra diante da postulaçáo do inconsciente. A perfeita coincidência do sujeito consigo próprio, enquanto consciência, fundaria uma identidade estável, unificada e única, que a psicanálise veio denunciar como impossível. Nesse sentido é que Touraine (1994) vai dizer que Freud é um dos grandes críticos do modelo racionalista.

Já dizia Freud em Uma dificuldade no caminho da Psicanálise (1917/1980) que a impossibilidade do domínio completo das pulsóes e a inconsciência dos processos mentais, eram proposiçóes extremamente penosas ao narcisismo, e à pretensão humana do êxito de uma autodeterminação completa de si próprio através da consciência.

Ao desalojar o ego da sua própria casa Freud postula a divisão do sujeito. Isso significa dizer que o eu comportará sempre um desconhecimento em relação a si próprio, já que o que o move é o desejo que, no entanto, é inconsciente. Esse desejo inconsciente jamais será totalmente apropriado, porque está remetido a uma falta constituinte, que perdurará enquanto existir o sujeito. Não encontraremos, dessa forma, um eu unívoco e coerente, mas marcado pela divisão, pelo recalque, como uma "das condiçôes estruturais da mente" (FREUD, 1923/1980, p. 30), portanto que esse desconhecimento estaria reportado à própria condição de existência do sujeito. 
Ao postular o narcisismo em 1914, Freud nos indica como a imagem plena de "Sua majestade o bebê" (FREUD, 1914/1980, p. 108) seria possibilidade de existência do sujeito. Num momento onde a dependência é absoluta ao outro, as categorias narcísicas de imortalidade, onipotência, auto-suficiência creditadas pelo outro são fundamentais à constituição de um sujeito frágil, finito. Num momento em que não há propriamente sujeito, mas pulsões anárquicas, um corpo vivido como despedaçado e uma alienação total ao outro, o narcisismo se apresenta como possibilidade de existência, envolve uma nova açâo psíquica (FREUD, 1914/1980, p. 93) que ao oferecer ao sujeito uma matriz, uma unidade para uma total dispersão, fundamenta a própria constituição do eu. Assim, "é a partir da onipotência que o outro lhe credita que o sujeito surge afirmativamente" (PINHEIRO, JORDÁO \& MARTINS, 1998, p. 163), marcando com isso que o sujeito não é em si, não está pronto na semente, mas surge a partir da alteridade. Isso é importante porque introduz uma dimensão de desconhecimento do sujeito em relação a si próprio, pois se ele toma essa imagem que o outro the credita como sendo sua, se identifica com ela para que exista, ele jamais será idêntico a essa imagem, ela continua sendo "emprestada". Desta forma, se o sujeito se identifica em seu sentimento de si com a imagem do outro, o que é próprio, o que é seu nessa imagem "emprestada" ele não sabe, sendo um estrangeiro na sua própria casa (LACAN, 1949/1998).

Se na infância, esse "empréstimo" entra menos em questão, porque os pais respondem pela existência do filho (até em termos da lei!) que, para poder existir, tomará essa verdade imediatamente como sua, quando aparece, a partir da puberdade, a possibilidade de mudança na posição de filho, essa suposta garantia de existência pode vir a ser estremecida. $\mathrm{O}$ desconhecido pode bater à porta do imediatamente conhecido, o que será denunciado através da angústia. Nessa ótica, a significação do tempo próprio, teria que levar em conta esse entrave a mais: os sujeitos não estão tão livres nessa significação, mas sofrem uma determinação que lhes atravessa, a determinação inconsciente, que desconhecem.

Se a psicologia destacou a importância da tarefa de se individualizar, desenvolver o sentido de individualidade, adquirir independência psicológica dos pais (HERBERT, 1991, p. 18), a psicanálise complicou um pouco mais a questáo da possibilidade de liberdade, já que para ela não existe esse indivíduo único, mas um sujeito dividido. Portanto, o processo não se passaria apenas entre o indivíduo e um outro exterior, como os pais da realidade por exemplo, num movimento de separaçáo - individuação, mas envolveria o sujeito num "quebra-cabeça” também intrapsíquico, que colocaria em jogo o próprio desconhecimento do sujeito em relação a si mesmo. Portanto, acrescenta-se um processo de transformação efetuado no interior do aparelho psíquico, fora do nosso espaço habitual, perceptível aos sentidos.

Nesse sentido, o tornar-se sujeito não implicaria apenas uma separação dos pais, ou o desligamento psíquico da autoridade parental (que seria facilmente substituída por outros representantes), mas também significaria a possibilidade de rompimento do assujeitamento do eu a este outro psíquico, ainda que nessa batalha não haja ganhador ou perdedor definitivo, porque o sujeito jamais seria uma unidade coerente. 
Qual a saída para o impasse? Teriam os sujeitos em geral possibilidade de construir um destino pessoal? Como buscar a sonhada liberdade delineada pelo projeto moderno, se determinados por uma força estranha e inconsciente?

Antes de privilegiarmos uma visada pessimista ou otimista da obra freudiana em relaçáo ao sujeito, faz-se mister indicarmos a riqueza da coexistência de indeterminismo e determinismo como dois aspectos centrais do pensamento de Freud em relação ao sujeito (HERZOG, 2000, p. 79). Por um lado, ele realmente póe em xeque a liberdade humana ao postular a determinaçáo inconsciente e o rochedo da castração (FREUD, 1937/1980), mas, da mesma forma, mantém um crédito na liberdade do sujeito a partir do momento que acredita num acesso à verdade, a partir de um conhecimento novo, pois "o relacionamento analítico se baseia no amor à verdade - isto é, no reconhecimento da realidade - e que isso exclui qualquer tipo de impostura ou engano" (FREUD, 1937/1980, p. 282).

Nesse sentido, se o sujeito não pode tudo - duro golpe no racionalismo, descrito por Freud em 1917 -, não significa dizer que nada pode.

O que pode, então, o sujeito? Que tipo de domínio, construção, será possível para esse sujeito que não mais tem na razão a garantia última de liberdade?

Tornar o destino pessoal desligando-se da autoridade parental significa tornarse sujeito, ao invés de assujeitado ao domínio do outro, colocado fora do sujeito. Mas, a partir do momento que esse outro passa a ser entendido como "dentro" do próprio sujeito, concernente a ele, porque é o outro psíquico dele mesmo, desconhecido, esse movimento não se dará do interior ao exterior, o sujeito tendo como "inimigo" a autoridade externa que terá que combater, mas o "inimigo" também diz respeito a ele próprio. Nesse sentido, poder trilhar uma trajetória onde o rompimento com o assujeitamento seja uma tônica, é também tornar-se "sujeito de si". Portanto singularizar o destino, torná-lo próprio, é também tornar-se sujeito.

Gondar (1995), ao analisar o pensamento trágico, vai mostrar como esse cenário de 'luta' passa a ser concernente ao sujeito. No Édipo de Sófocles, por exemplo, a situação trágica por excelência não seria seus atos propriamente ditos, mas que ele tenha que interrogar uma exterioridade - portanto que ele não saiba - sobre o seu lugar e o seu destino.

Se é a partir desse mal-estar que haverá a interrogação de si, então, temos uma chave para pensar que esse desconhecimento, marca da tragédia humana, e causa de mal-estar, é também o que movimenta o sujeito, porque é só a partir dele que um questionamento se tornará necessário, do contrário "ficamos onde estamos". Nesse sentido, esse desconhecimento nos constitui e nos destitui, mas na medida em que nos destitui, ou seja, que causa mal estar perturbando o já estabelecido, também abre a possibilidade da interrogação, e da busca de sentidos mais condizentes com a verdade própria de cada um.

Touraine, amplamente influenciado por esta visão psicanalítica que descentra a unicidade de um eu, vai dizer "o que eu denomino Sujeito é uma reflexão do indi- 
víduo sobre sua própria identidade" (TOURAINE, 1994, p. 289). Portanto, sujeito não se confunde jamais com identidade, com aquilo que supomos ser, mas é justamente a pergunta desestabilizante de uma identidade já posta, configurada. Sujeito é elemento de discordância de um estabelecido.

A herança do projeto moderno, que é a possibilidade do sujeito se colocar como ator, sentir-se participante da sua história pessoal, portanto indo contra um destino exterior, é um dos seus maiores legados. A liberdade ancorada sobre a idéia do futuro como um vir-a-ser, mas sem um destino já delineado (BEZERRA JÚNIOR, 2000). Se o sujeito pretende construir o seu destino, temos que a destinação é a significar, depende de um trabalho do sujeito. Mas, se o sentido é fluído e depende do sujeito, entâo este pode tudo? Teríamos a possibilidade magnânima de tudo criar, escolher, construir? Se isso fosse possível, então, provavelmente ficaríamos paralisados diante de tão grande tarefa. É nesse ponto que a história, tanto coletiva quanto individual, se apresenta como importante nessa empreitada. Por exemplo, se sou brasileiro, nascido no século XX, em tal família, significa que parto de um já dado, que contém certa composição, pertenço a uma história, a um ethos, a um tempo específico, portanto o que sou é também a partir disso que já está aí. Se não tenho a visão como sentido decifrante do mundo, sem dúvida minha linguagem será composta a partir de outros sentidos. Há uma determinação já posta, certo campo do qual se parte, que não é infinito, mas já se deu num tempo. No entanto, se é fundamental o reconhecimento desse campo necessário, apenas reconhecê-lo não é suficiente, com o risco de cairmos, mais uma vez, numa concepção fatalista do tempo, da história e do destino. O que, então, é preciso não esquecermos? Da permanente tensão, do jogo de forças que se presentifica na significação, uma tensão permanente, um "não resolvido por si”, entre o já instituído e a possibilidade de transformá-lo. Desta forma, é preciso sim considerar a surdez, a cegueira, a pobreza, enfim os significados que envolvem o campo do qual se parte, sabendo que eles jamais darão uma definição cabal de quem é o sujeito.

Fazendo uma contraposição entre indivíduo, sujeito e ator, tendo como base as noções freudianas de id, ego e superego, Touraine (1994) vai dizer que para definir os termos é preciso fazê-lo em relação uns com os outros. Para que seja viável a construção de um sujeito individual, é preciso que o indivíduo reconheça nele a presença do si-mesmo junto com a vontade de ser sujeito. Só há produçáo do sujeito à medida que a vida resiste no indivíduo e, em vez de aparecer como um monstro a ser combatido, é aceita como libido ou sexualidade e se transforma em esforço para construir a unidade de uma pessoa. O Sujeito estaria relacionado ao domínio sobre o vivido para que tenha um sentido pessoal, para que o indivíduo se transforme em ator, que se insere nas relaçôes sociais e as transforma, mas que não se identifica totalmente com o lugar que ocupa nas organizaçôes sociais, não se conforma ao lugar que ocupa (TOURAINE, 1994, p. 221).

Entendemos, então, que não há sujeito fora do indivíduo, ou melhor, se a categoria que privilegiamos é a de sujeito, é imprescindível que não esqueçamos que não há liberdade possível para o sujeito quando se desconsidera sua condição de 
indivíduo histórico. Não há sujeito fora da história, mesmo quando nos referimos à desrazão inconsciente.

\section{outro da ação educativa: diferente?}

As novas políticas inclusivas acarretam na prática certa desconstrução da concepção de diferença que até entáo vigorava, porque aproximam o que antes podia ficar "afastado". Nesse sentido, se o deficiente auditivo, visual, mental era agrupado num lugar específico, ao participar de classes regulares ele traz para o cerne do cotidiano escolar uma nova presença que obriga, necessariamente, professores e alunos a reorganizar as significaçôes de diferença previamente estabelecidas. Quem é este ser, comunga da mesma "natureza humana" que a minha? Encontra-se em desvantagem? $\mathrm{O}$ que fazer com ele? Pequenas perguntas que comportam grandes concepçôes de mundo e que assolam professores que se encontram às voltas com as questôes práticas que redundam das novas políticas A questão central relacionada à ação inclusiva refere-se à possibilidade de convivência com a diferença. Nesse sentido, infelizmente, açôes concretas de inclusão nem sempre tem como correlato a aceitação simbólica da diferença. Parece que o aprender a viver com os outros, pilar essencial da educação (DELORS, 2004), fica dificultado e esmaecido quando se trata de alguém onde a desigualdade sobrepuja a semelhança. Desta forma, interrogar-se quem é este outro que a ação educativa pretende incluir, faz-se premissa necessária a qualquer propósito responsável. Se o sujeito alvo da açáo inclusiva tem como premissa necessária a exclusão, a pergunta imediata é: de quê? Do mundo dos ouvintes, dos falantes, dos que vêem, dos que têm capital... Aqui nos interessa ressaltar que por trás de qualquer concepção escolhida para interpretar o outro repousará certo ideário de destino. Que relação o desprovido de capital tem com sua pobreza? $\mathrm{O}$ surdo com sua incapacidade para ouvir? Ora, estas perguntas parecem óbvias, mas de fato elas não o são. Podemos certamente vitimizar o diferente, acreditá-lo como um coitado que a sorte não premiou. Ou, como fala Carvalho (2004), ter para com ele atitudes de comiseraçáo. Nesses casos o retiramos de seu lugar de agente do mundo e de si próprio. Estaríamos, como Freud bem mostrou, acreditando num destino já traçado, numa sorte já escrita, que independe do sujeito. Sob este ponto de vista o destino permaneceria como algo exterior, uma autoridade longínqua, diante da qual pouco se poderia fazer. Se, por outro lado, náo levarmos em conta o que lhe é próprio, qual sua particular história podemos recair na falácia individualista de que "só é pobre quem não se esforça", por exemplo. Assim, aprofundar o questionamento sobre o outro, desconfiar das explicaçóes simplificadas, pode ser um bom começo para entendermos que o psíquico percorre meandros bastante complexos.

Se consideramos que o destino é a significar, e não já dado, que contém uma possibilidade de combinações múltiplas, temos que lidar com a tensão permanente da construção de sua significação. Se a significação não está garantida, o sujeito não só terá que abrir mão de todas as outras possibilidades, ao efetuar uma, como jamais terá a certeza da escolha certa. Se não há certezas e garantias, se não há previsibilidade, não há como se precaver de erros, enganos, imprevistos. Portanto, aceitar a diferença é poder conviver com a nossa própria condição de desconhecimento em relação a 
nós mesmos, é visualizar que o caminho humano estará sempre marcado por certa errância.

\section{À guisa de conclusão}

Iniciamos nosso trabalho indicando a importância de refletirmos sobre o ideário de "natureza humana" que subjaz a toda e qualquer situação que envolva processos educativos. Mais particularmente destacamos a centralidade desta empreitada quando se pretende uma educação que considere a diferença. A partir do momento que a concepção de destino permeia este ideário, direta ou indiretamente, já que se articula às questôes de liberdade e autonomia, fazer um percurso na obra freudiana sobre o conceito tornou-se aprofundamento necessário. $\mathrm{O}$ que a psicanálise vem nos mostrar é a divisão do sujeito, a impossibilidade de tudo saber, tudo controlar. A pretensão de uma autonomia plena não é possível quando pensamos no sujeito inconsciente. Ainda assim, a busca da liberdade continua sendo bússola importante para as trajetórias humanas. É nesta direção que a psicanálise nos indica um caminho: o conhecimento de sua própria verdade e desejo. Portanto, a diferença não está apenas no outro, mas refere-se ao próprio desconhecimento que cada um tem para consigo mesmo. Desta forma, as concepçôes de destino oferecem uma reflexão que deve envolver o sujeito com o outro que é ele mesmo. Não há, assim, possibilidade de aceitação da diferença se não levarmos em conta que a diferença também está em nós mesmos.

\section{Referências}

BEZERRA JÚNIOR, B. A retomada do futuro: tempo e utopia na subjetividade contemporânea. In: JOBIM E SOUZA, S. (Org.). Mosaico: imagens do conhecimento Rio de Janeiro: Rios Ambiciosos, 2000. p. 81-95.

CARVALHO, R. Educaçáo inclusiva com os pingos nos “is”. Porto Alegre: Mediação, 2004.

DELORS, J. (Org.). Educação um tesouro a descobrir. Tradução de J. Eufrázio. São Paulo: Cortez, 2004. (Original publicado em 1996).

DOLTO, F. A imagem inconsciente do corpo. Tradução de N. Kon. São Paulo: Perspectiva. 1992. (Original publicado em 1984).

FREUD, S. Três ensaios sobre a Teoria da Sexualidade. Tradução de J. Salomão. Edição standard brasileira das obras psicológicas completas de Sigmund Freud, volume VII, Rio de Janeiro: Imago, 1980. (Original publicado em 1905).

Sobre o Narcisismo: uma introdução. Tradução de J. Salomão. Ediçẫo standard brasileira das obras psicológicas completas de Sigmund Freud, volume XIV, Rio de Janeiro: Imago, 1980. (Original publicado em 1914).

Sobre a transitoriedade. Tradução de J. Salomão. Edição standard brasileira das obras psicológicas completas de Sigmund Freud, volume XIV, Rio de Janeiro: Imago, 1980. (Original publicado em 1915).

. O Inconsciente. Tradução de J. Salomão. Ediçâo standard brasileira das obras psicológicas completas de Sigmund Freud, volume XIV, Rio de Janeiro: Imago, 1980. (Original publicado em 1915).

Uma dificuldade no caminho da Psicanálise. Tradução de J. Salomão. Edição standard brasileira das obras psicológicas completas de Sigmund Freud, volume XVII, Rio de Janeiro: Imago, 1980. (Original publicado em 1917).

O Ego e o Id. Tradução de J. Salomão. ESB, volume XIX, Rio de Janeiro: Imago, 1980. (Original publicado em 1923).

O Problema Econômico do Masoquismo. Tradução de J. Salomão. Edição standard brasileira das obras psicológicas completas de Sigmund Freud, volume XIX, Rio de Janeiro: Imago, 1980. (Original publicado em 1924). 
FREUD, S. Inibiçóes, sintomas e ansiedade. Tradução de J. Salomão. Edição standard brasileira das obras psicológicas completas de Sigmund Freud, volume XX, Rio de Janeiro: Imago, 1980. (Original publicado em 1926).

Análise terminável e interminável. Tradução de J. Salomâo. Ediçấo standard brasileira das obras psicológicas completas de Sigmund Freud, volume XXIII, Rio de Janeiro: Imago, 1980. (Original publicado em 1937)

A divisáo do Ego no processo de defesa. Tradução de J. Salomão. Edição standard brasileira das obras psicológicas completas de Sigmund Freud, volume XXIII, Rio de Janeiro: Imago, 1980. (Original publicado em 1938).

GONDAR, J. Os tempos de Freud. Rio de Janeiro, Rio de Janeiro: Revinter, 1995.

HERBERT, M. Convivendo com adolescentes. Rio de Janeiro: Bertrand Brasil, 1991.

HERZOG, R. A noção de singularidade do sujeito a partir da teoria freudiana. Tese de Doutorado, Pontifícia Universidade Católica do Rio de Janeiro, Departamento de Psicologia, 1992. 343 f.

LACAN, J. O estádio do espelho. Traduçáo de V. Ribeiro. In: Escritos. São Paulo: Perspectiva, 1949/1998. (Publicação original 1966).

LAPlANCHE, J.; PONTALIS, J. B. Vocabulário da Psicanálise. Rio de Janeiro: Martins Fontes, 1992.

PINHEIRO, T.; JORDÃO, A.; MARTINS, K. A certeza de si e o ato de perdoar. Cadernos de Psicanálise SPCRJ, v. 14, n. 17, p. 161-172, 1998.

SACRISTÁN, J. G. Os novos liberais e os velhos conservadores perante a educação. In: PACHECO, J. (Org.) Políticas educativas, o neoliberalismo em educaçáo. Porto, Portugal, Ed. Porto, 2000.

TOURAINE, A. Critica da modernidade. Tradução de E. Edel. Petrópolis: Vozes, 1994.

\section{Notas}

${ }^{1}$ Freud (1924/1980) usa a palavra Destino com letra maiúscula referindo-se a esse destino referido à autoridade parental, com poderes supremos que escapariam ao sujeito. Já em 1930, quando se utiliza do mesmo vocábulo, o faz sem letra maiúscula referindo-se ao destino de forma menos absoluta e exterior.

2 Freud discute essa crença de que "não morreremos" em Sobre a transitoriedade (FREUD,1916-15/1980). Podemos encontrar outros textos nos quais ele discute a negação da morte, a não inscriçấo da morte no sistema inconsciente, como no texto metapsicológico O Inconsciente (FREUD, 1915/1980), a correlaçáo da morte ao narcisismo (FREUD, 1914/1980).

${ }^{3} \mathrm{O}$ termo desamparo se refere ao "estado do lactente que, dependendo inteiramente de outrem para a satisfação de suas necessidades (sede, fome) é impotente para realizar a ação específica adequada para por fim à tensão interna" (LAPLANCHE \& PONTALIS, 1992, p. 112). Em 1926, em Inibição, sintoma e angústia, Freud vai representar o desamparo como a situaçáo traumática por excelência, sendo origem da angústia.

\section{Correspondência}

Cristiana Carneiro - Universidade Federal do Rio de Janeiro, Faculdade de Educação. Avenida Pasteur, Botafogo, CEP: 22290-902 - Rio de Janeiro, Rio de Janeiro - Brasil.

E-mail: cristianacarneiro13@gmail.com

Recebido em 04 de novembro de 2015

Aprovado em 07 de março de 2016 